Developmental Biology

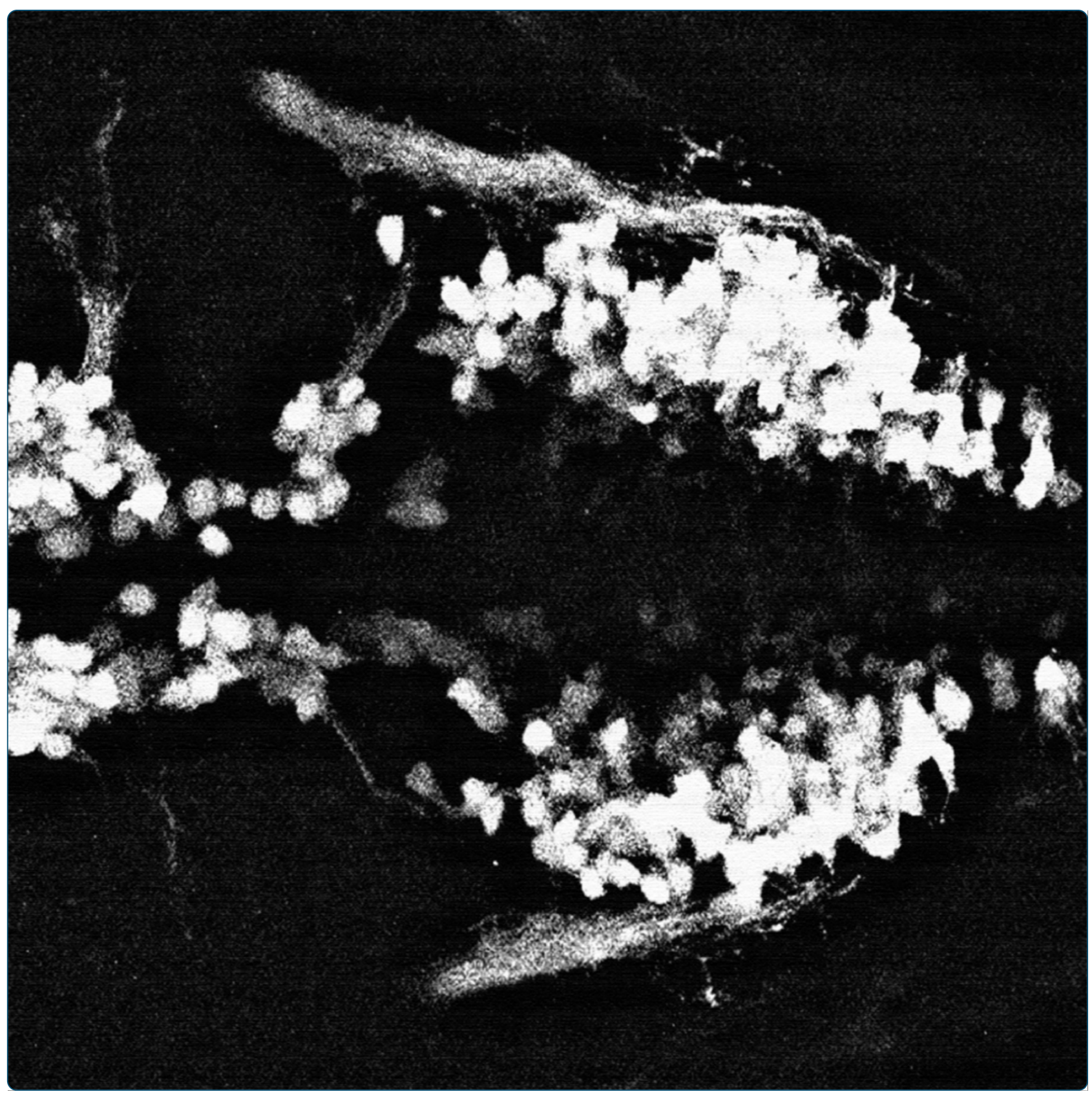

The role of Zic transcription factors in regulating hindbrain retinoic acid signaling

Drummond et al. 


\title{
The role of Zic transcription factors in regulating hindbrain retinoic acid signaling
}

\author{
Danna L Drummond ${ }^{1}$, Caroline S Cheng ${ }^{1}$, Lyndsay G Selland ${ }^{1}$, Jennifer C Hocking ${ }^{1}$, Lisa B Prichard ${ }^{2}$ \\ and Andrew J Waskiewicz ${ }^{1,3,4^{*}}$
}

\begin{abstract}
Background: The reiterated architecture of cranial motor neurons aligns with the segmented structure of the embryonic vertebrate hindbrain. Anterior-posterior identity of cranial motor neurons depends, in part, on retinoic acid signaling levels. The early vertebrate embryo maintains a balance between retinoic acid synthetic and degradative zones on the basis of reciprocal expression domains of the retinoic acid synthesis gene aldhehyde dehydrogenase 1a2 (aldh1a2) posteriorly and the oxidative gene cytochrome p450 type 26a1 (cyp26a1) in the forebrain, midbrain, and anterior hindbrain.
\end{abstract}

Results: This manuscript investigates the role of zinc finger of the cerebellum (zic) transcription factors in regulating levels of retinoic acid and differentiation of cranial motor neurons. Depletion of zebrafish Zic2a and Zic2b results in a strong downregulation of aldh $1 a 2$ expression and a concomitant reduction in activity of a retinoid-dependent transgene. The vagal motor neuron phenotype caused by loss of Zic $2 \mathrm{a} / 2 \mathrm{~b}$ mimics a depletion of Aldh1a2 and is rescued by exogenously supplied retinoic acid.

Conclusion: Zic transcription factors function in patterning hindbrain motor neurons through their regulation of embryonic retinoic acid signaling.

\section{Background}

During development, the vertebrate hindbrain is transiently divided into a series of lineage-restricted segments, termed rhombomeres, through the expression of distinct transcription factors. Notably, anterior-posterior patterning and segmentation of the hindbrain is critical in appropriately specifying neuronal cell types [1-5]. The identity of each hindbrain segment is regulated by the Hox family of homeobox transcription factors, the anterior expression limits of which correlate precisely with rhombomere boundaries [6-18]. The correct complement of hox genes expressed within each hindbrain segment specifies the identity of cells within that segment by activating regional expression of cell migration and axon guidance molecules. Blocking the functions of Hox proteins or their $\mathrm{Pbx}$ (Pre-B cell leukemia) and Meis (Myeloid ecotropic virus integration site) cofactors

\footnotetext{
* Correspondence: aw@ualberta.ca

'Department of Biological Sciences, University of Alberta, CW405, Edmonton, AB T6G 2E9, Canada

${ }^{3}$ Centre for Neuroscience, University of Alberta, Edmonton, Canada

Full list of author information is available at the end of the article
}

within the hindbrain leads to changes in rhombomere identity and corresponding defects in cranial motor neuron migration and axon guidance [6,17,19-21].

The vitamin A-derived morphogen retinoic acid (RA) regulates anterior-posterior patterning of the neural tube, including defining regional identity of hindbrain segments [22-28]. For example, vitamin A-deficient quail embryos lack posterior rhombomeres r4-r8 [24,25]. Maintaining the precise level of retinoic acid is critical, with increased levels known to result in teratogenic defects of the forebrain, heart, and eyes [24,29]. In the hindbrain, segmentation defects associated with changes in retinoic acid are attributed to alterations in hox gene expression [9,27,30-33]. For example, an increase in retinoic acid levels causes expansion of the posterior hindbrain hox-4 expression [31,32], while a deficiency in retinoic acid causes an embryonic loss of hox-1, hox-3, and hox 4 paralog expression domains $[16,17,26,28]$.

Regional specificity of retinoic acid signaling is achieved in part through restricted domains of Retinaldehyde dehydrogenase proteins (Raldh, encoded by the aldh1a gene family), the enzymes that catalyze the rate-limiting step in
Ciomed Central

(c) 2013 Drummond et al.; licensee BioMed Central Ltd. This is an Open Access article distributed under the terms of the Creative Commons Attribution License (http://creativecommons.org/licenses/by/2.0), which permits unrestricted use, distribution, and reproduction in any medium, provided the original work is properly cited. 
RA synthesis [34,35]. Pharmacologic blockade of Raldh activity using diethylaminobenzaldehyde (DEAB) results in ablation of the posterior hindbrain, a phenotype that is highly analogous to the vitamin A-deficient quail $[26,36]$. The heme-thiolate family of cytochrome p450 type 26 enzymes (cyp26a1/b1/c1) hydroxylate RA, a modification that targets it for degradation $[37,38]$. The forebrain, midbrain and anterior hindbrain express cyp 26 genes, thereby blocking RA signaling in these regions [39-43]. The combined activity of posteriorly expressed aldh1a with anterior-specific cyp 26 genes creates a defined zone of RA signaling within the presumptive hindbrain. RA activity is mediated intracellularly by two nuclear receptor families, retinoid-X-receptor (RXR) and retinoic acid receptor (RAR) [44-46]. Ligand-bound heterodimeric RXR:RAR complexes activate transcription of genes containing retinoic acid response elements (RAREs). Analysis of conserved non-coding elements surrounding hox- 1 and hox- 4 paralogs has identified RAREs that are essential to rhombomere-specific expression of hox-1/hox-4 genes in the hindbrain $[11,31,34,47,48]$. In support, alterations in RA levels result in profound defects to hox -1 and hox-4 gene expression domains $[11,31,34,47,48]$.

Although the role and requirement of retinoic acid metabolism genes during embryogenesis has been extensively studied, the factors acting to initiate and maintain expression of RA metabolism genes remain largely unknown. Within vertebrates, transcription factors from the Zic (Zinc Finger of the Cerebellum) family of transcription factors are dynamically expressed in partially overlapping regions of the neural tube, indicative of a role in neural development. Recent evidence suggests a connection between Zic transcription factors and the retinoic acid signaling pathway: Maurus et al. demonstrated that loss of zebrafish Zic1 causes a decrease in presumptive forebrain expression of cyp26a1 and an increase in RA signaling as detected by RARE:eGFP transgenics [49]. Further, mutations in human ZIC2 result in holoprosencephaly (HPE), a forebrain defect where the cerebral hemispheres fail to separate during development $[50,51]$ and HPE phenotypes have been connected to aberrant RA signaling, thus providing a plausible link between Zic2 and retinoic acid metabolism $[29,36,52,53]$. Based on these observations, we tested the hypothesis that Zic transcription factors play a key role in the initiation and maintenance of RA metabolism gene expression during zebrafish embryogenesis. The data presented here demonstrate that zebrafish zic2 genes act upstream of retinoic acid metabolism and suggest a novel regulatory interaction between Zic2a and Zic2b transcription factors and the RA-synthesizing gene aldh1a2. Further, we show that Zic2 signaling is necessary for proper hindbrain patterning.

\section{Results and discussion}

\section{Zic transcription factors are expressed during the initiation of RA metabolism genes}

Retinoic acid levels are regulated by the precise action of synthesis and hydroxylation genes. Aldehyde dehydrogenase 1a2 (Aldh1a2, also known as Raldh2), the ratelimiting synthetic enzyme, catalyzes the conversion of retinal to retinoic acid $[34,35,38]$. The transcription of aldh1a2 is initiated early in development, with expression at the embryonic margin at 5 hours post fertilization (hpf) (Figure 1A) and in lateral plate mesoderm by $8 \mathrm{hpf}-10 \mathrm{hpf}$ (Figure 1B-C') [26,54,55]. Beginning at $18 \mathrm{hpf}$, aldh1a2 expression is restricted to the dorsal retina and anterior somites (Figure 1D). Retinoic acid degradation occurs following its hydroxylation by the cytochrome p450 oxidase, Cyp26a1. cyp26a1 transcription is initiated early during zebrafish embryogenesis, starting with the presumptive anterior neural ectoderm at $5 \mathrm{hpf}$ (Figure 1E) [56,57]. By early somitogenesis (10 hpf), cyp26a1 mRNA is found in the presumptive forebrain, midbrain, anterior hindbrain, and part of the tailbud (Figure 1G, G'). At the later somitogenesis stages of 16-21 hpf, its expression becomes restricted to parts of the retina, caudal notochord, and tailbud (Figure $1 \mathrm{H}$ ).

To ascertain whether Zic transcription factors could regulate embryonic initiation of RA metabolism, we first examined which of the seven zebrafish zics are present during the time when cyp26a1 and aldh1a2 mRNA expression are initiated. Using in situ hybridization in conjunction with known expression data, we determined that $z i c 1, z i c 2 a, z i c 2 b$, and $z i c 3$ are the best candidates for driving initiation of RA metabolism genes because they are expressed at the earliest stages of development [58-60]. zic2a, zic2b, and zic3 are all expressed broadly by $5 \mathrm{hpf}$, while zic1 expression is not detectable (Figure 1I, $\mathrm{M}, \mathrm{Q}, \mathrm{U})$. By 8-10 hpf, zic1 and zic $2 a$ are expressed in discrete regions consistent with cyp26a1 expression within the anterior neural ectoderm (Figure 1J-K', M-O'). zic $2 b$ and zic3 show broad dorsal expression domains by $8 \mathrm{hpf}$, in regions that overlap with both anterior expression of cyp $26 a 1$ and the more posterior expression domain of aldh1a2 (Figure $1 \mathrm{R}, \mathrm{V}$ ). As development continues, the zics display expression within the dorsal hindbrain, extending down the spinal cord in varying levels and degrees, showing less obvious overlap with cyp26a1 and aldh1a2 (Figure 1L, P, S-T, W-X). Overall, these data show that $z i c 2 a / 2 b / 3$ transcription factor expression is consistent both temporally and spatially with the initiation of expression of cyp26a1 and aldh1a2. To ensure that zic gene expression corresponds to the same germ layers as cyp $26 a 1$ and aldh1a2, we sectioned 90\% epiboly (9 hpf) embryos following in situ hybridization. While cyp $26 a 1$ is expressed in the epiblast, and aldh1a2 is limited to the hypoblast, $z i c 2 a$ and $z i c 2 b$ are present 


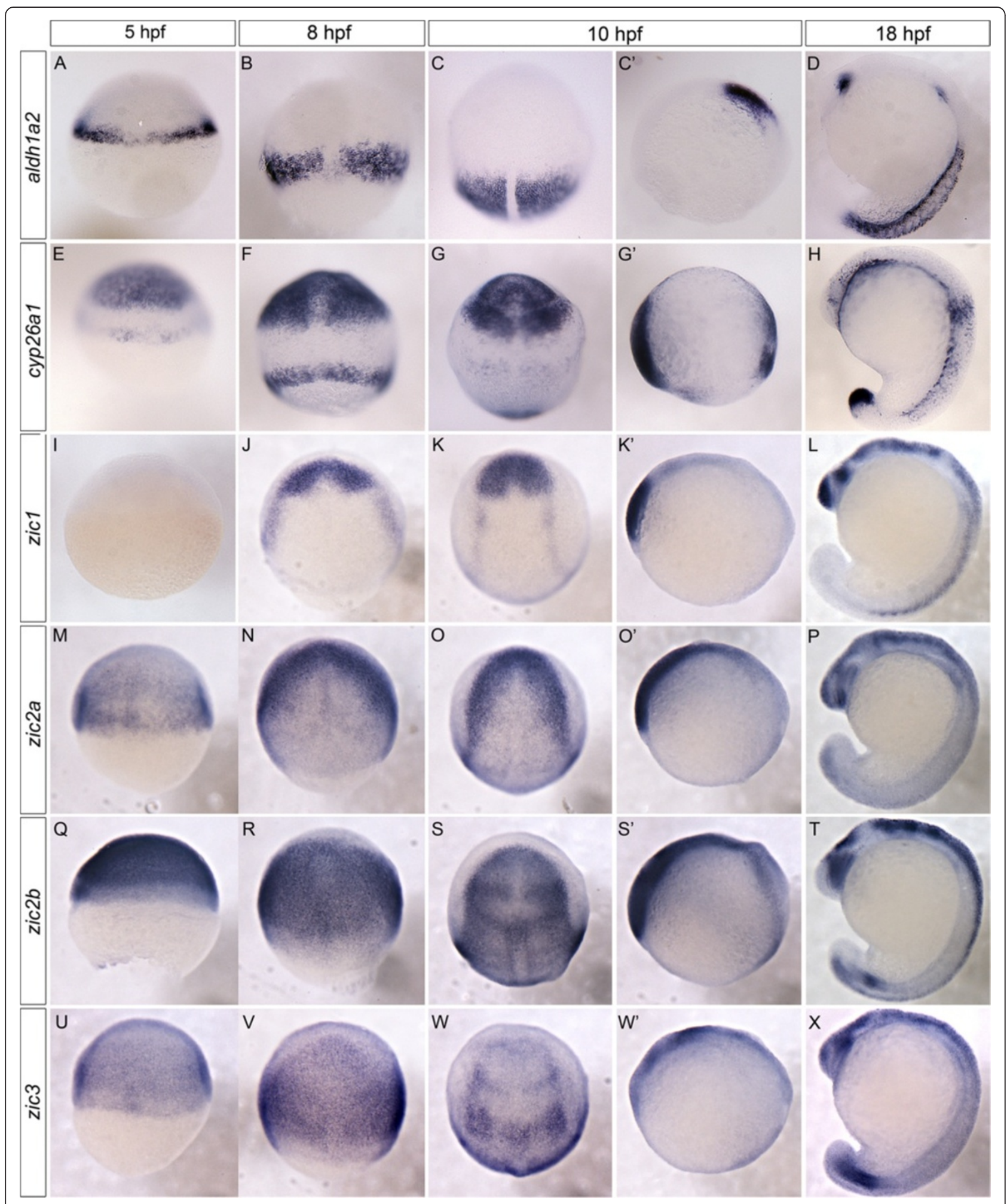

Figure 1 (See legend on next page.) 


\section{(See figure on previous page.)}

Figure 1 Temporal and spatial analysis of zic transcription factors and key RA synthesis and degradation genes. aldh 1a2 expression is restricted to the embryonic margin at 5 hpf (A). By 8-10 hpf aldh1a2 is observed in the lateral plate mesoderm (B, C, C'). At 18 hpf, aldh1a2 is expressed in the dorsal retina and anterior somites (D). cyp26a1 is expressed in the embryonic margin and the presumptive anterior neural ectoderm at 5-8 hpf (E, F). By 10-18 hpf cyp26a1 is expressed in presumptive forebrain, midbrain, anterior hindbrain, retina, and part of the tailbud (G, G', H). zic1 is not detectable until 8-10 hpf (75\% epiboly), when it is expressed within the presumptive anterior neural tissue (I, J, K, K'). By 18 hpf, zic 1 is expressed strongly in the telencephalon, midbrain-hindbrain boundary, dorsal hindbrain and spinal cord (L). zicza initiates earlier, with dorsally-restricted expression at $5 \mathrm{hpf}(50 \%$ epiboly) (M). By 8-10 hpf zic2a becomes anteriorly restricted within presumptive anterior neural tissue with additional midline expression (N, $\mathbf{O}, \mathbf{O}^{\prime}$ ). By 18 hpf, zic2a is within the anterior forebrain, ventral eye, dorsal hindbrain and spinal cord (P). Initially, zic2b is expressed in a broad domain encompassing the dorsal side of the embryo (Q; 5 hpf). This broad expression is maintained at $8 \mathrm{hpf}(\mathbf{R})$ and 10-18 hpf where expression is strongest within the eye, midbrain-hindbrain boundary, and presumptive hindbrain $\left.\mathbf{( S ,} \mathbf{S}^{\prime}, \mathbf{T}\right)$. zic3 is also dorsally restricted at 5-8 $\mathbf{h p f}(\mathbf{U}, \mathbf{V})$. At 10-18 hpf, zic3 is within the presumptive telencephalon, posterior forebrain, midbrain-hindbrain boundary and dorsal hindbrain, and within the tailbud $\left(\mathbf{W}, \mathbf{W}^{\prime}, \mathbf{X}\right)$. Images are dorsal views with anterior to top (A-C, E-G, I-K, $\left.\mathbf{M}-\mathbf{O}, \mathbf{Q}-\mathbf{S}, \mathbf{U}-\mathbf{W}\right)$ or lateral views with anterior to left (C', D, G', H, K', L, O', P, S', T, W', X). hpf: hours post fertilization.

diffusely in both germ layers and are therefore coexpressed with both RA metabolism genes (Figure 2A-D).

\section{Zics act upstream of early retinoic acid metabolism genes, cyp26a1 and aldh1a2}

Based on our observations of zic gene expression, the earliest expressed genes $z i c 2 a, z i c 2 b$, and $z i c 3$ were examined for possible roles in the initiation of RA metabolism. Due to the propensity for functional redundancy, we chose first to simultaneously knock down three transcription factors, Zic2a, Zic2b, and Zic3 with antisense morpholino oligonucleotides. Upon examining resulting phenotypes, we determined that Zic3 depletion is dispensable, and the Zic3 morpholino was removed from the injection mixture. Interestingly, embryos injected with splice-blocking morpholinos for Zic2a and Zic2b display a reduction in cyp26a1 (Figure 3A, B) and aldh1a2 (Figure 3C, D) expression by 7 hpf. While both the cyp26a1 expression level and domain are reduced, the aldh1a2 expression domain is reduced in size, but normal in intensity of staining. Results from quantitative real-time PCR showed a $29 \%$ reduction in aldh1a2 expression in Zic2a2b-depleted embryos as compared to control embryos (p-value $\leq 0.0001$, unpaired $t$-test) (Figure 3E). The downregulation of aldh1a2 expression in Zic2a2b-depleted embryos can be observed as late as $18 \mathrm{hpf}$ and $24 \mathrm{hpf}$ (Figure 3F, G and Figure 3H, I respectively); however it is not as profound as the reduction seen in 7 hpf embryos.

\section{Zic depletion causes mild alterations to retinoic acid-responsive genes and hindbrain patterning}

As Aldh1a2 and Cyp26a1 have opposing effects on RA levels, the knockdown of either gene alone would be expected to produce opposite phenotypes. However, since Zic2a2b depletion reduces both RA metabolism genes simultaneously, the outcome for RA signaling is difficult to predict. Thus, we performed in situ hybridization for retinoic acid-responsive genes to ascertain the overall level of retinoic acid signaling in Zic-depleted embryos. Previous work demonstrated that the expression levels of zebrafish meis3, hoxb1a, hoxd4a, and hnflba correlate with changing retinoic acid levels (Hernandez et al., 2004, Huang et al., 2002, Kudoh et al., 2002, Moroni et al., 1993, Zhang et al., 2000). Our results show a strong reduction in meis 3 and a mild reduction in hoxd4a expression within the presumptive hindbrain following Zic2a2b knockdown (Figure 4A, B, E, F). Two other retinoic acid-responsive genes, hoxbla and hnflba, did not show significant changes in

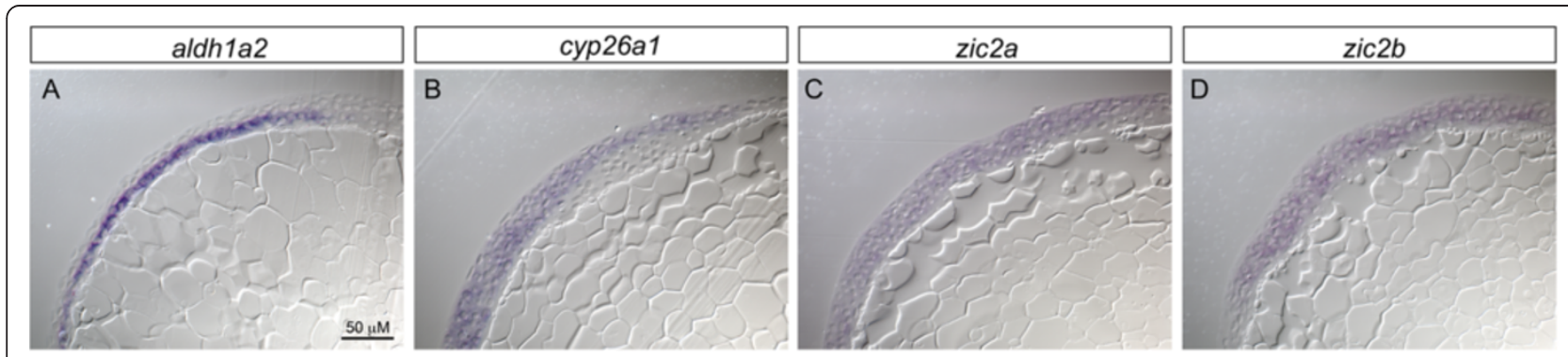

Figure 2 zic $2 a$ and zic $2 b$ are co-expressed with aldh1a2 and cyp26a1 in the early embryo. 90\% epiboly embryos were processed for in situ hybridization for aldh1a2, cyp26a1, zic2a or zic2b, and subsequently mounted in JB-4 resin and cut into $7 \mu \mathrm{M}$ sections on a microtome. aldh1a2 expression is clearly limited to the hypoblast (A), while cyp26a1 is present in the epiblast (B). In contrast, zic2a and zic2b each show broad expression across the germ layers (C,D). 


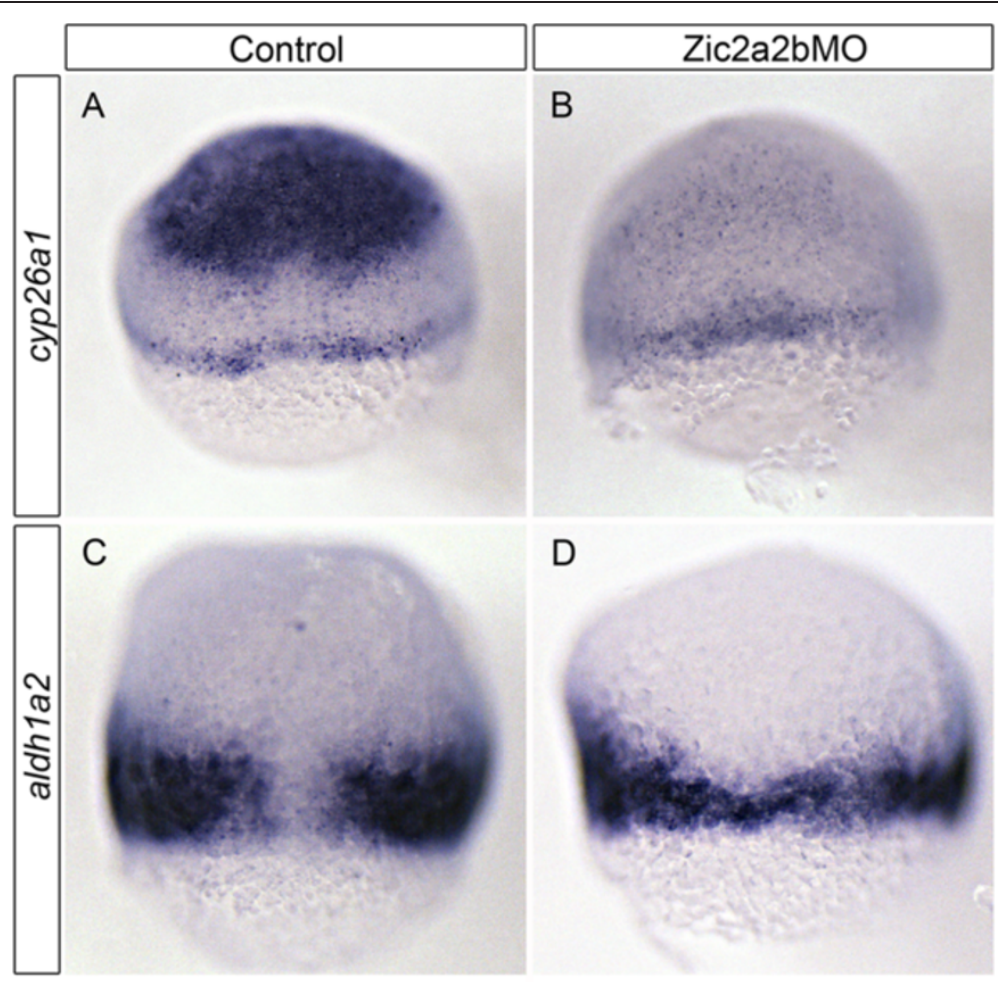

E

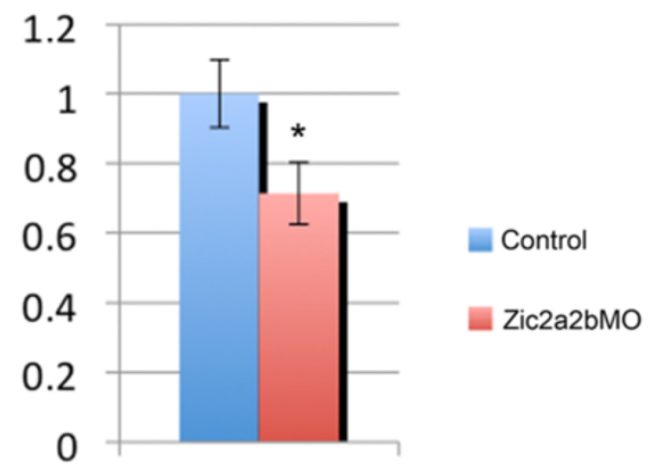

Aldh1a2
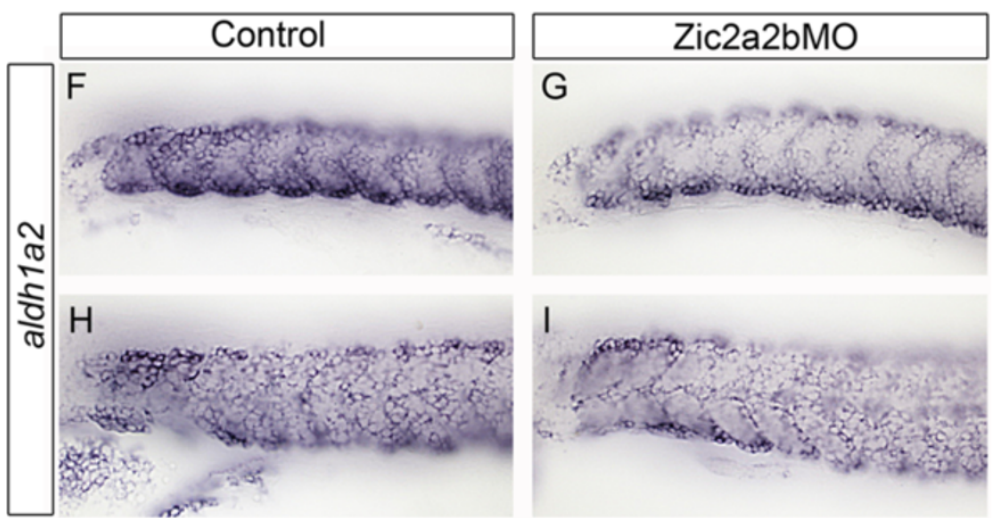

Figure $\mathbf{3}$ (See legend on next page.) 
(See figure on previous page.)

Figure $3 \mathrm{Zic} 2 \mathrm{a}$ and Zic2b depletion causes down-regulation of the retinoid-metabolism genes, cyp26a1 and aldh1a2, during early embryogenesis. mRNA in situ hybridization analysis of cyp26a1 (A, B) and aldh1a2 (C, D, F-I) expression reveals a reduction in both genes in Zic2a;Zic2b;p53 morpholino injected embryos (B, D, G, I) compared to control p53-morpholino injected embryos (A, C, F, H). Relative aldh1a2 mRNA expression levels for $7 \mathrm{hpf}$ embryos were determined using quantitative real-time PCR (E). Levels reflect average of 7 technical replicates, with aldh1a2 mRNA at 0.71 significantly reduced $\left(S D=0.11 ;{ }^{*} p<0.0001\right)$ compared to normalized control. Images are of 7 hpf embryos in dorsal view with anterior oriented to top (A-D), or lateral views with anterior to the left of $18 \mathrm{hpf}(\mathbf{F}, \mathbf{G})$ or $24 \mathrm{hpf}$ embryos $(\mathbf{H}, \mathbf{I})$. Error bars depict standard deviation.

expression with Zic2a2b morpholino when compared to uninjected controls (Figure 4C, D, G, H). To determine whether the reductions in meis 3 and hoxd $4 a$ are caused by changes to retinoic acid signaling, we treated zic $2 a 2 b$ morphants with $5 \mathrm{nM}$ retinoic acid. Indeed, $5 \mathrm{nM}$ RA is able to rescue the expression of meis 3 and hoxd4a to levels similar to those seen in our uninjected controls (Figure 5A-H). In addition, morpholino knockdown of aldh1a2 causes a similar reduction in meis 3 and hoxd4a to that seen in zic $2 a 2 b$ morphants (Figure $5 \mathrm{I}-\mathrm{L}$ ). Thus, our data strongly argue that Zic2a2b promote the expression of RA-responsive genes through Aldh1a2.

We took advantage of manipulating RA levels to further examine the regulatory loops present in the early zebrafish embryo. Given that zic $2 a 2 b$ morpholinos cause a loss in cyp26a1 expression, it is plausible that this causes an indirect effect on the aldh1a2 domain. To test this, we examined expression of aldh1a2 in mutants lacking cyp26a1. Notably, aldh1a2 levels are unaffected in cyp26a1(giraffe) mutants, arguing against a scenario whereby the aldh $1 a 2$ reduction in $z i c 2 a 2 b$ morphants occurs because of reduced hydroxylation of RA by Cyp26a1 (Figure 5M, N).

Based on the observation that retinoic acid signaling is reduced in zic2a $2 b$ morphants, we examined whether $z i c 2 a 2 b$ depletion also led to defects in hindbrain patterning. In situ hybridization for hindbrain markers (krox20, mafba, hoxb4a, hoxb1a, egfl6) was performed to examine hindbrain segmentation and rhombomere morphology (Figure 6). We found that all rhombomeres are formed, but that rhombomeres 3 and 5 (egr $2 b / k r o x 20$ expression) are reduced in size (Figure $6 \mathrm{C}, \mathrm{D}$ ) and there is reduced hoxa $2 b$ expression within r2-r6 (Figure 6A, B). In addition, hoxb4a expression within the posterior hindbrain and spinal cord is also reduced (Figure 6C, D). Other regions within the hindbrain appear normal as observed through appropriate marker expression patterns (Figure 6E-L). This suggests that although there is a reduction in the posterior neural domain, the reduction of retinoic acid signaling in $z i c 2 a 2 b$ morphants does not lead to a complete loss of posterior regions.

\section{Zic2a2b depletion reduces retinoic acid signaling}

The transgenic zebrafish line $\operatorname{Tg}(12 x R A R E \text {-ef1a:eGFP })^{\text {sk71 }}$ contains twelve retinoic acid response elements (RAREs) upstream of a ubiquitous promoter linked to the gene for enhanced green fluorescent protein, eGFP [61,62]. Active retinoic acid signaling in $\mathrm{Tg}(12 \times R A R E-e f 1 a: e G F P)^{\text {sk71 }}$ fish can be detected either directly by observation of eGFP fluorescence, or by in situ hybridization for eGFP mRNA. The sensitivity of this transgenic line was examined by assaying its response to alterations in retinoic acid levels (Figure 7). In 26 and $48 \mathrm{hpf}$ control embryos, the predominant regions of retinoic acid signaling are within the spinal cord and posterior hindbrain (Figure 7B, E, H, K, N). As expected, the fluorescence domain is increased at both stages in response to retinoic acid treatment, expanding further anteriorly into the hindbrain and posteriorly down the spinal cord (Figure 7C, F, I, L, O). At $48 \mathrm{hpf}$, there are additional retinoic acid signaling centers within the dorsal and ventral eye (Figure 7H', K). Here, exogenous addition of retinoic acid results in morphologically smaller eyes and loss of the dorsal expression domain, while the ventral eGFP-positive region is maintained (Figure 7I', L). Blocking retinoic acid synthesis with $D E A B$ treatment results in a loss of all retinoic acid signaling, with no fluorescence or in situ coloration visible at $26 \mathrm{hpf}$ or $48 \mathrm{hpf}$ (Figure 7D, G, J, J', M, P). These results demonstrate that the $\mathrm{Tg}$ $(12 x R A R E-e f 1 a: e G F P)^{\text {sk71 }}$ zebrafish line is a suitable tool for studying retinoic acid signaling. Of note, we were unable to detect the transgene before $24 \mathrm{hpf}$, preventing the analysis of retinoic acid signaling levels at early embryonic stages, when retinoic acid metabolism genes are first transcribed.

As the $\operatorname{Tg}(12 x R A R E$-efla:eGFP $)$ transgenic line labels posterior retinoic acid signaling regions, we asked whether the reduction in retinoic acid metabolism genes following Zic depletion leads to an alteration in later embryonic retinoic acid signaling levels. As compared to control $e G F P$ levels (Figure 8A, B), there is a strong reduction in $e G F P$ expression in $75 \%$ of the $z i c 2 a 2 b$ morphant embryos at $26 \mathrm{hpf}$ (Figure $8 \mathrm{C}, \mathrm{D}, \mathrm{E}$ ). This suggests that there is a reduction in retinoic acid signaling within the Zic2a2bdepleted hindbrain at later stages. To test the hypothesis that the reduction in retinoic acid signaling in $z i c 2 a 2 b$ morphants is a result of reduced aldh1a2 expression, we compared retinoic acid signaling between Aldh1a2depleted and Cyp26a1-depleted embryos. eGFP levels appear only slightly affected in cyp26a1 MO-injected embryos as compared to control (Figure 8A, F). How- 

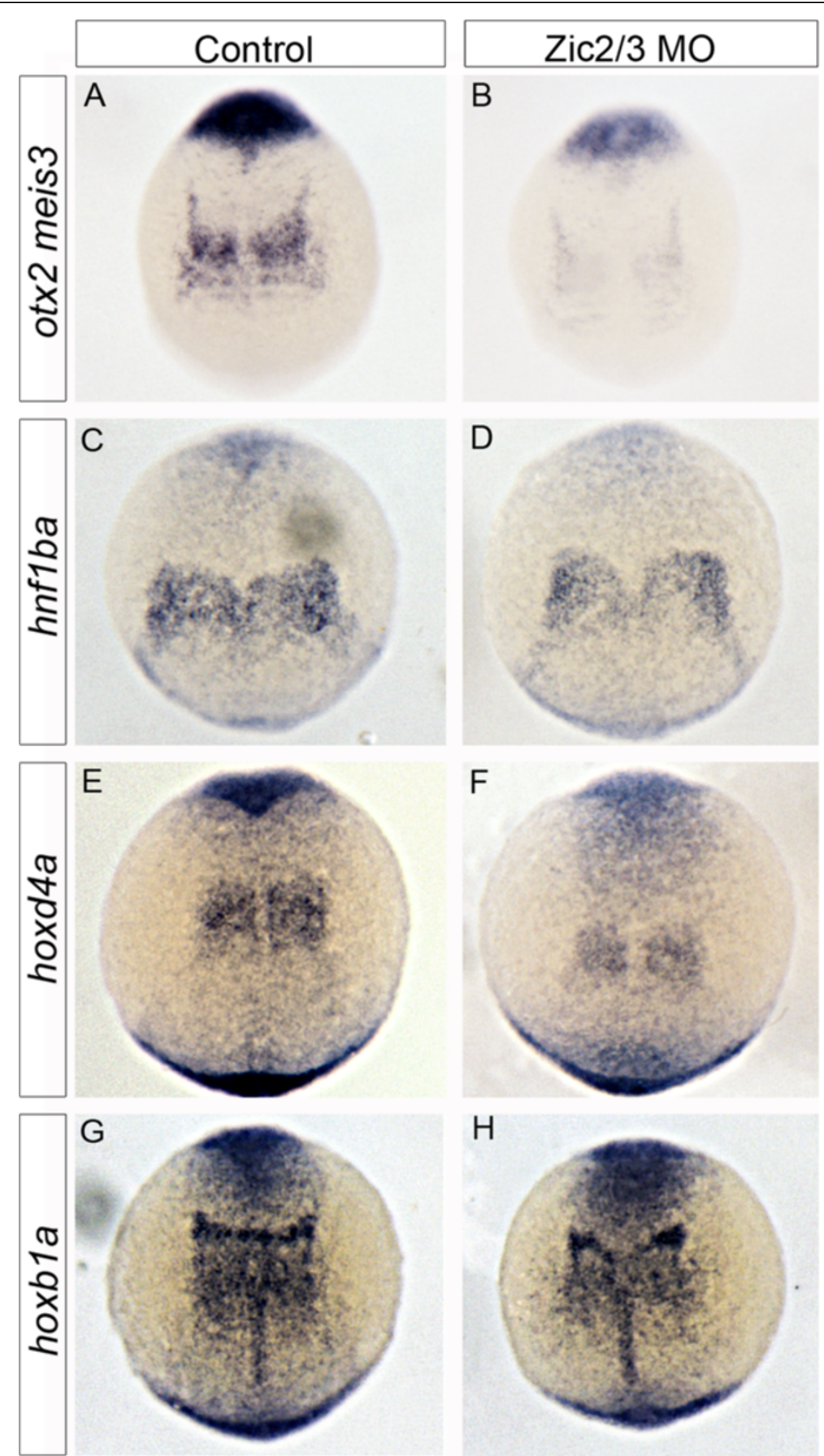

Figure 4 Retinoic acid-responsive gene expression in Zic morpholino-injected embryos. mRNA transcript expression of RA-dependent markers meis3 and otx2 (A, B), hnfiba (C, D), hoxd4a (E, F), and hoxb1a (G, H) were compared in control uninjected $(\mathbf{A}, \mathbf{C}, \mathbf{E}, \mathbf{G})$ and Zic2a;Zic2b;Zic3MO-injected embryos (B, D, F, H). Although hoxb1a and hnflba are largely unchanged, a decrease in meis3 and hoxd4a is observed in Zic morpholino-injected embryos. All images are of 10.5 hpf embryos in dorsal views with anterior oriented to top.

ever, strikingly, there is a strong reduction in retinoic acid signaling levels across both Zic2a2b and Aldh1a2 knockdowns, as shown by strong reduction of eGFP transcript as compared to controls (Figure 8A, C, G).
Taken together, these data show that we have identified a novel regulatory mechanism whereby Zic2a2b regulates retinoic acid levels, most likely through the regulation of aldh1a2 transcription. 


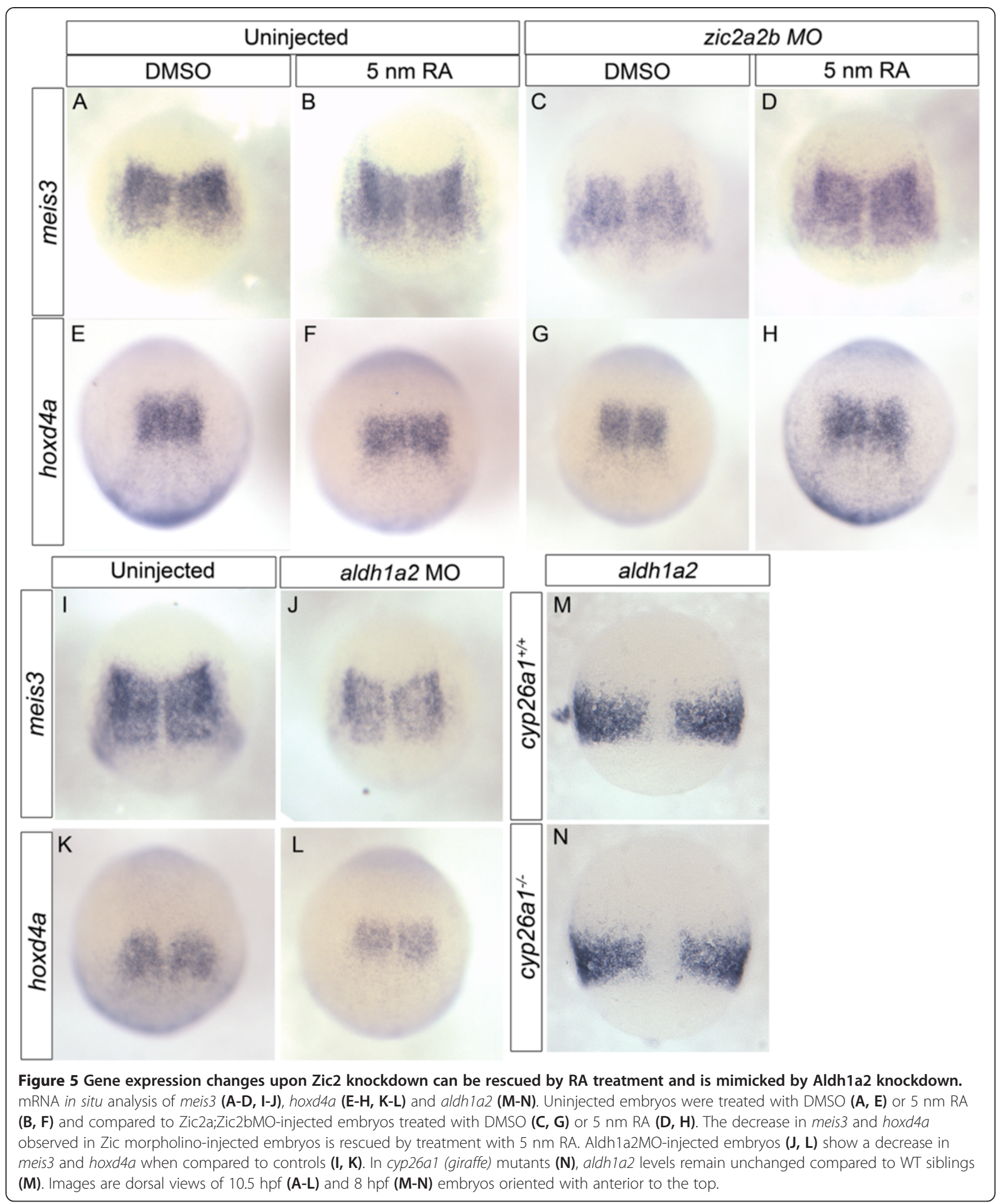

\section{Vagal neurons are sensitive to alterations in retinoic} acid levels

Our results demonstrated strong deficits in RA signaling at $26 \mathrm{hpf}$, a key time-point for specification and differentiation of hindbrain branchiomotor neurons [1]. To determine the developmental consequence of the reduction in retinoic acid signaling, we chose to examine development of vagal motor neurons within the posterior hindbrain and 


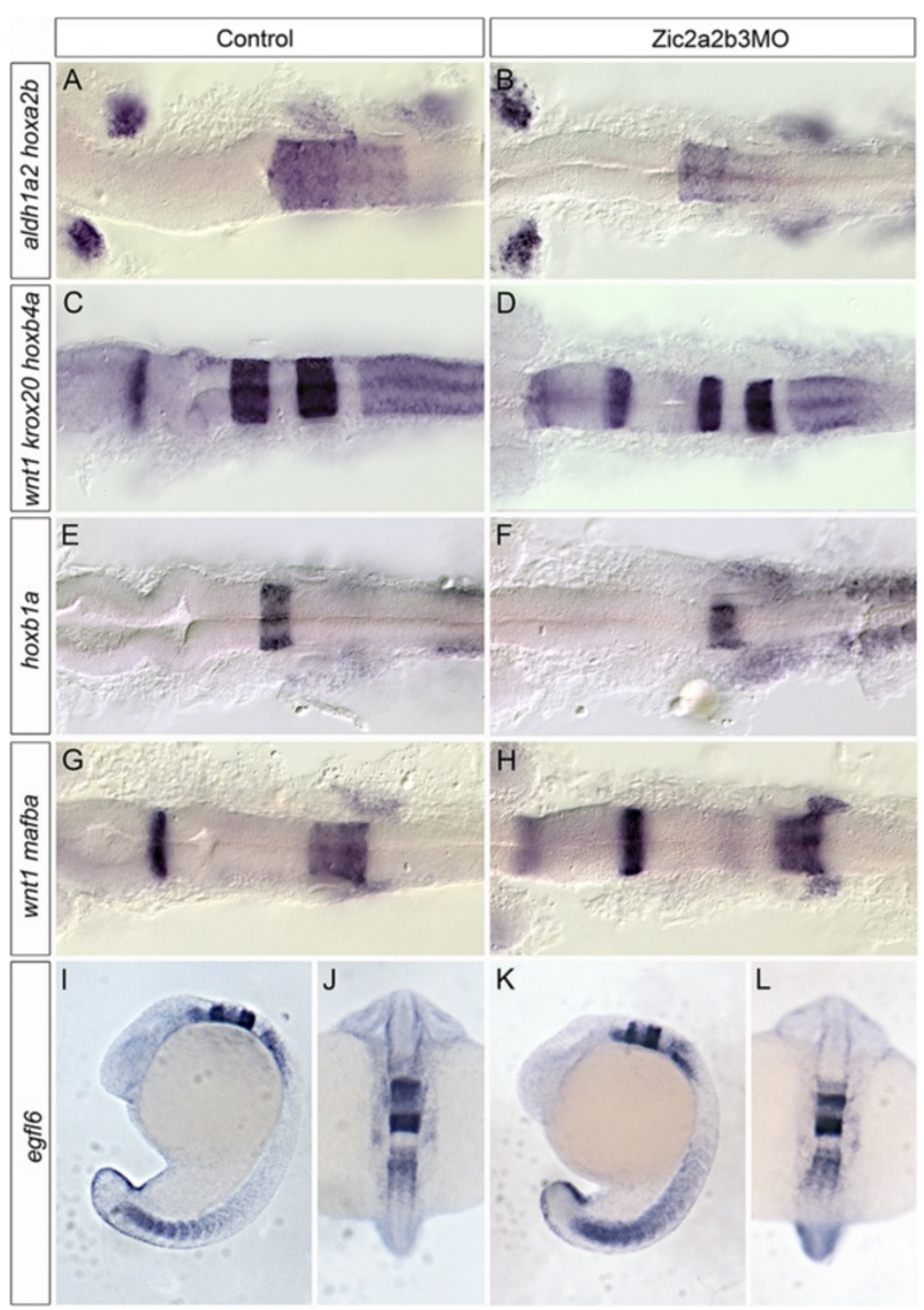

Figure 6 Hindbrain patterning in Zic morpholino-injected embryos. mRNA expression of hindbrain segmentation markers hoxa2b/aldh1a2 (A, B), krox20/hoxb4a/wnt1 (C, D), hoxb1a (E,F), mafba/wnt1 (G, H), and egfl6 (I-L) were examined in control uninjected (A, C, E, G, I, J) and Zic2a;Zic2b;Zic3MO-injected embryos (B, D, F, H, K, L). We note a reduction in hoxa2b expression in Zic morphant embryos (compare $\mathbf{B}$ to $\mathbf{A}$ ) as well as a thinning of rhombomeres 3 and 5 , as labeled by krox20 expression (compare $\mathbf{D}$ to $\mathbf{C}$ ). Expression of hoxb4a is reduced (compare $\mathbf{D}$ to C), but other markers of segment identity are overtly normal (E-L). Embryos are shown in dorsal $(\mathbf{A}-\mathbf{H}, \mathbf{J}, \mathbf{L})$ or lateral $\mathbf{( I ,} \mathbf{K})$ views and are 18 hpf.

spinal cord [55]. Using the $\operatorname{Tg}(i s l 1: e G F P)$ transgenic line, we sought to analyze development of hindbrain branchiomotor neurons by confocal microscopy in response to Zic2a2b depletion [63]. In control embryos, trigeminal neuron cell bodies are located within rhombomeres 2 and 3 , facial neurons within rhombomeres 5 and 6 , and the vagal neuron domain extends from the posterior hindbrain down the spinal cord (Figure 9A, D). To estimate the number of vagal neurons, we used ImageJ to quantify the area and length of the vagal neuron cluster (Figure 9G, $\mathrm{H})$. Upon treatment with retinoic acid, the vagal domain is greatly expanded and more neuronal cell bodies are visible as compared to control (Figure 9B, E, G, H). The average area in DMSO-treated control embryos is $5481 \mu \mathrm{m}^{2}$
$\left(\mathrm{SD}=321 \mu \mathrm{m}^{2}\right)$ and the anterior-posterior length is $165 \mu \mathrm{m}(\mathrm{SD}=4.5 \mu \mathrm{m})$. Treatment with RA results in an average area of $10,353 \mu^{2}\left(\mathrm{SD}=1448 \mu \mathrm{m}^{2}\right.$; p-value $\leq 0.01$ ) and length of $214 \mu \mathrm{m}(\mathrm{SD}=11 \mu \mathrm{m} ; \mathrm{p}$-value $\leq 0.01)$. Alternatively, treatment with $\mathrm{DEAB}$, a pharmacological inhibitor of retinoic acid synthesis, significantly alters embryonic patterning such that all posterior rhombomeres are lost. The vagal domain is almost undetectable in these embryos (Figure 9C, F, G, H). DEAB treatment also results in mispatterning of anterior branchiomotor neuron classes such that it is difficult to identify trigeminal, facial, and possible remnants of vagal neuron populations. As a best estimate, the area of vagal neurons in DEAB-treated embryos is $1683 \mu \mathrm{m}^{2}$ 


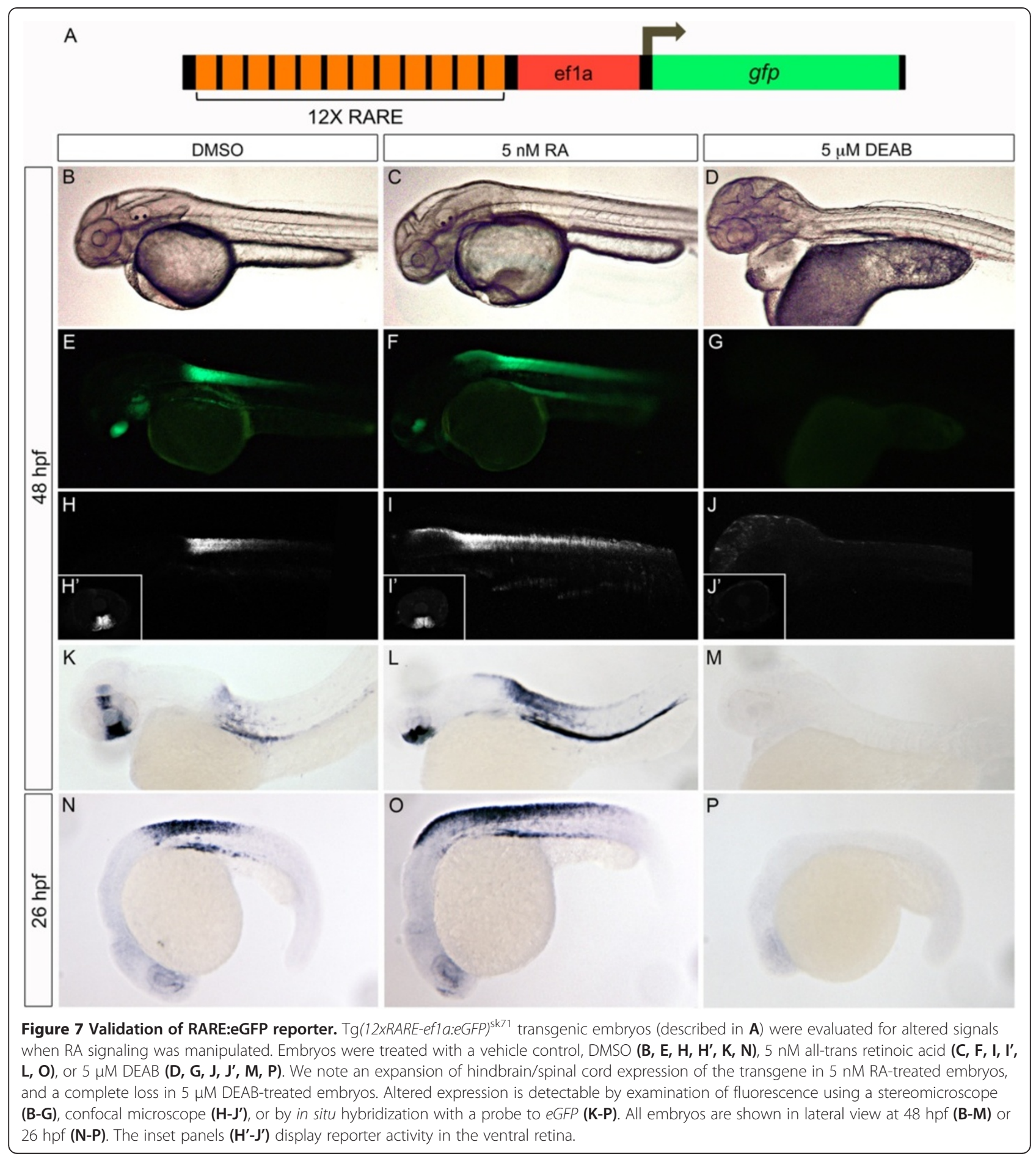

( $\mathrm{SD}=1264 \mu \mathrm{m}^{2} ; \mathrm{p}$-value $\left.\leq 0.01\right)$ and length is $65 \mu \mathrm{m}$ $(\mathrm{SD}=20 \mu \mathrm{m} ; \mathrm{p}$-value $\leq 0.01)$.

\section{Zic2a2b knockdown causes loss of vagal neurons}

Zic2a2b-depleted embryos have reduced retinoic acid signaling levels within the posterior hindbrain and spinal cord. To ascertain whether this reduction in retinoic acid signaling causes a concomitant defect in vagal motor neurons, Zic2a2b knockdown was introduced in $\operatorname{Tg}($ isl1:eGFP) transgenic zebrafish. Embryos were grown in media containing DMSO (control) or treated with exogenous retinoic acid $(1 \mathrm{nM})$ or DEAB $(1 \mu \mathrm{M})$ to determine if retinoic acid supplementation could rescue phenotypes. Zicdepleted embryos have significantly reduced vagal neuron 




area and length as compared to control embryos (Figure 10A, D, G, H). The average area of the vagal neuron domain in Zic-depleted embryos is $4979 \mu^{2}$ ( $\mathrm{SD}=$ $\left.1443 \mu \mathrm{m}^{2}\right)$ as compared to $7382.5 \mu \mathrm{m}^{2}(\mathrm{SD}=377.2)$ in controls. The average length of the vagal neuron domain is $126.4 \mu \mathrm{m}(\mathrm{SD}=13.8)$ as compared to $176.6 \mu \mathrm{m}(\mathrm{SD}=$ $10.5)$ in controls $(n=15$, p-value $<0.01)$. This reduction in the vagal neuron domain would be expected with a mild reduction in retinoic acid levels. In many cases, the medial-lateral width of each vagal population was increased in morphants, suggesting a possible migrational error, as vagal neurons are typically formed medially and migrate laterally during development [1]. The physiological level of retinoic acid is estimated to be $3 \mathrm{nM}$ $[64,65]$. Due to reduced retinoic levels in Zic-depleted embryos, we postulated that supplementation with near physiological levels $(1 \mathrm{nM})$ of retinoic acid (a concentration that does not cause significant alteration to control embryos) may be sufficient to rescue the neural phenotype seen. There is a mild increase in vagal neuron area and length in control embryos in response to $1 \mathrm{nM}$ retinoic acid treatment (Figure 10B, G, H). Strikingly, with low dose treatment of retinoic acid, the vagal neuron area of Zic-depleted embryos is rescued to values similar to those 


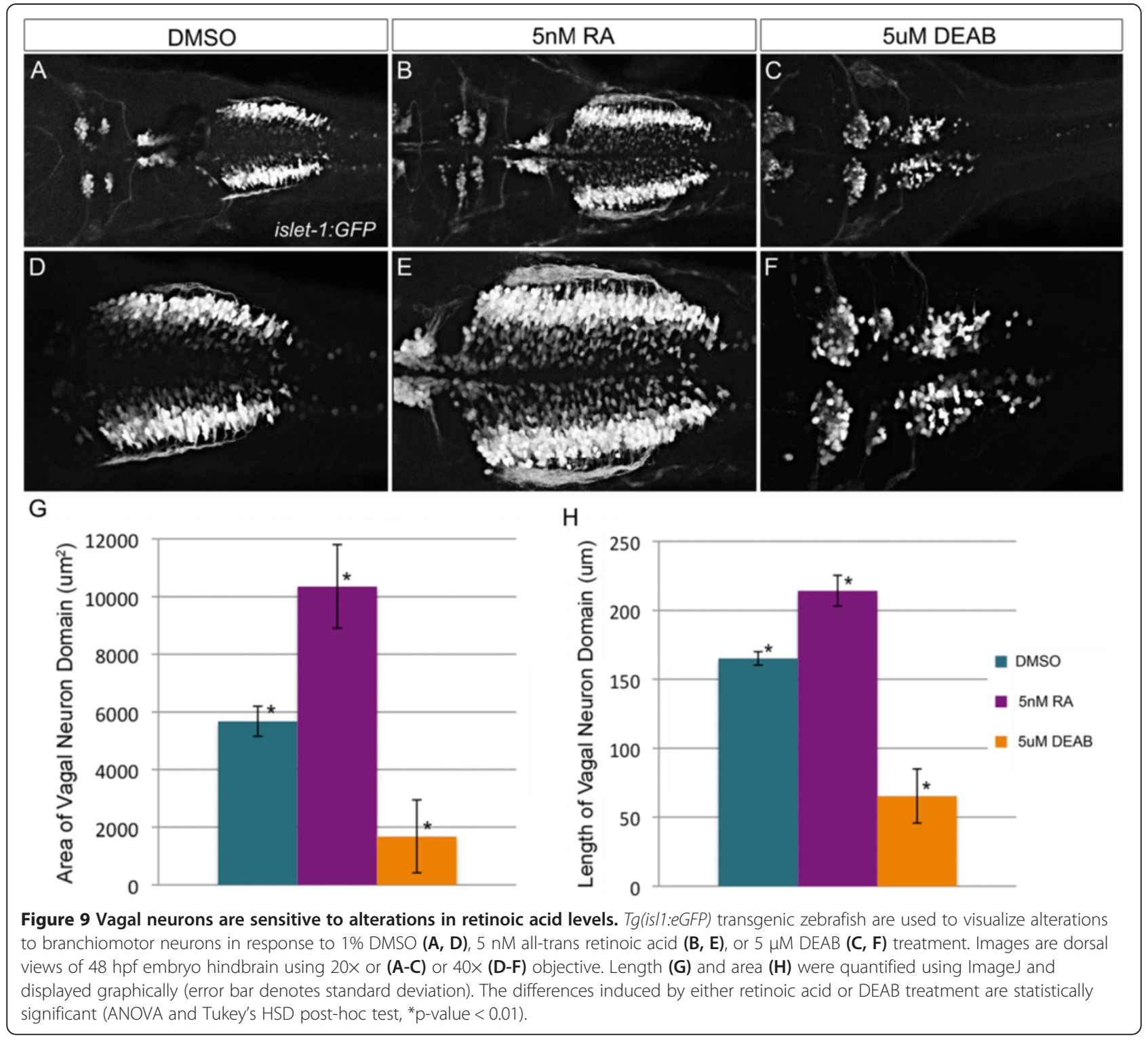

seen in control embryos: RA-treated, Zic-depleted embryos have an average vagal neuron area of of $8616.4 \mu \mathrm{m}^{2}$ $\left(\mathrm{SD}=1929 \mu^{2}\right)$ as compared to an average area in control embryos of $8963.8 \mu \mathrm{m}^{2}\left(\mathrm{SD}=1139.1 \mu \mathrm{m}^{2}\right)$ or $4979.3 \mu \mathrm{m}^{2}\left(\mathrm{SD}=1443 \mu \mathrm{m}^{2}\right)$ in DMSO-treated zic $2 a 2 b$ morphants. There is also a significant increase in the length of the vagal domain in $z i c 2 a 2 b$ morphants treated with retinoic acid as compared to morphants in DMSO (vehicle control) conditions (Figure 10D, E, G, H): RAtreated morphants have a vagal domain length of $156 \mu \mathrm{m}$ $(\mathrm{SD}=16 \mu \mathrm{m})$, compared to $126 \mu \mathrm{m}(\mathrm{SD}=14$; $\mathrm{p}$-value < 0.01 ; $\mathrm{n}=14$ ) for DMSO-treated morphants. While the domain length after RA treatment is similar to that of untreated control embryos, it is still significantly reduced compared to control embryos treated with retinoic acid. We asked whether zic2a2b morphants had residual RA by treating them with $D E A B$. By further reducing retinoic acid levels with DEAB treatment, there is a roughly equivalent shrinkage of the vagal neuron domain in both $z i c 2 a 2 b$ morphants and control embryos (Figure 10C, F, G, H).

Our data is consistent with a model whereby Zic2a and Zic2b act upstream of retinoic acid metabolism by activating transcription of aldh1a2. As shown, there is an early reduction in aldh1a2 transcript levels in Zic2a2b morphants, and the reduction in retinoic acid signaling levels within $\operatorname{Tg}(12 x R A R E-e f 1 a: e G F P)$ transgenics is similar in Zic2a2b and Aldh1a2-depleted embryos. Further, the reduction in vagal neurons in zic $2 a 2 b$ morphants is rescued by treatment with retinoic acid, the product of an Aldh1a2-catalyzed reaction. To determine if this relationship between Zic2a2b and aldh1a2 is 


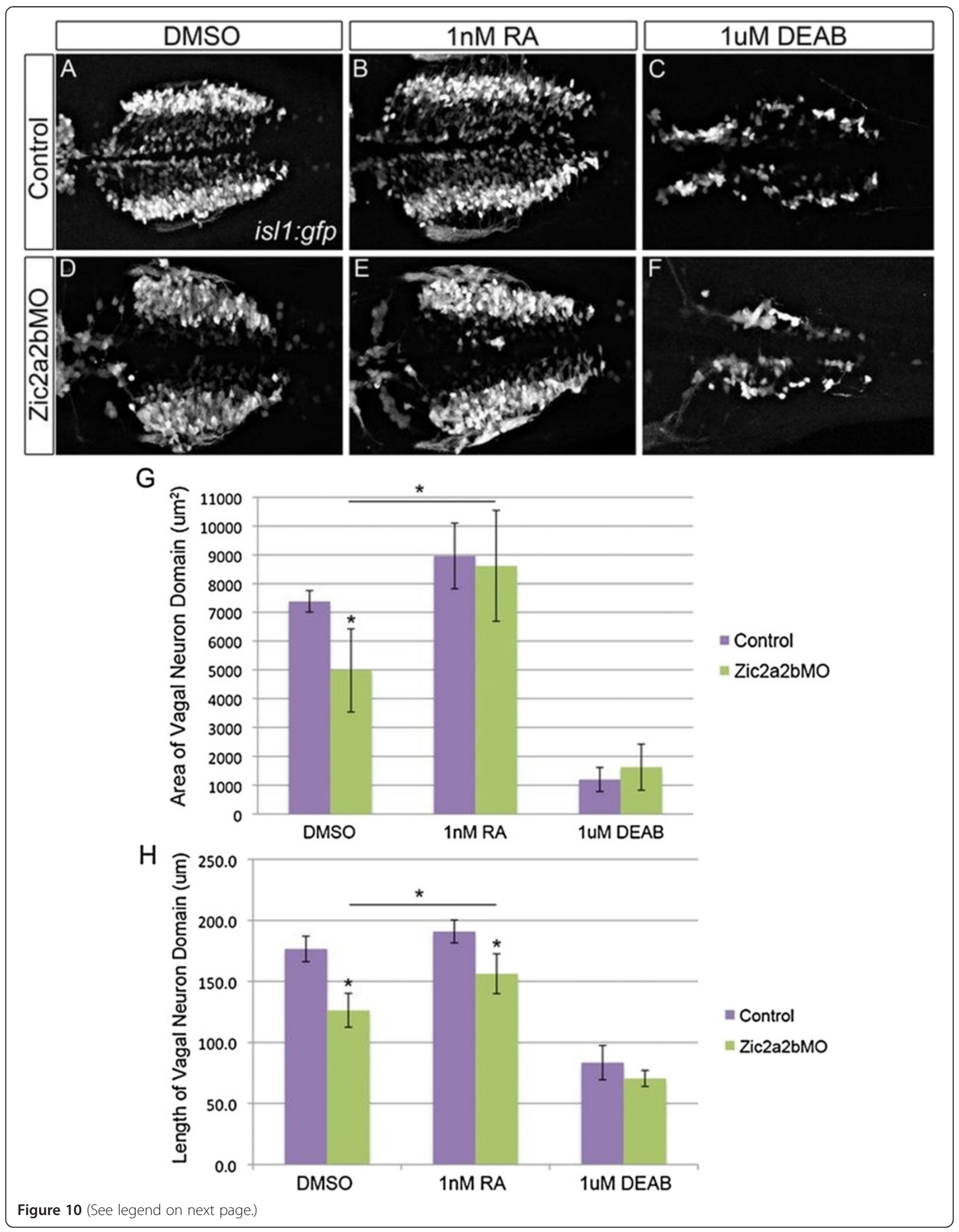


(See figure on previous page.)

Figure 10 Vagal neuron domain in Zic2a and Zic2b morpholino injected embryos is partially rescued with low doses of RA. Dorsal views of the vagal motor neurons in $48 \mathrm{hpf}$ Tg(is/1:eGFP) embryos that were injected with p53 morpholino (A-C) or Zic2a;Zic2b and p53 morpholinos (D-F), and treated with $1 \%$ DMSO (A, D), 1 nM RA (B, E), or $1 \mu \mathrm{M} \mathrm{DEAB} \mathrm{(C,} \mathrm{F).} \mathrm{Quantification} \mathrm{of} \mathrm{vagal} \mathrm{motor} \mathrm{neuron} \mathrm{domain} \mathrm{area} \mathrm{(G)} \mathrm{demonstrates}$ that Zic2a/2b depletion causes a statistically significant reduction in domain size, which is rescued by treatment with retinoic acid. Quantification of vagal neuron domain length $\mathbf{( H )}$ gives similar results, with a statistically significant reduction upon Zic2 depletion, which could again be counteracted by retinoic acid addition. Statistical significance calculated by ANOVA and Tukey's HSD post-hoc test ( ${ }^{*}$ p-value $\left.\leq 0.01\right)$.

maintained in later neurons, vagal neurons were examined in aldh1a2 morphant $\operatorname{Tg}($ isl1:eGFP) zebrafish. The Aldh1a2-depleted embryos also show a statistically significant reduction in length of the vagal domain, very similar to that seen in Zic2a2b-depleted embryos (compare Figures 10 and 11). The comparable reduction in vagal domain length supports the hypothesis that Zic $2 a 2 b$ act upstream of aldh1a2. Taken together, our data show that the most posterior class of branchiomotor neurons, the vagal neurons, is sensitive to alterations in retinoic acid levels. Increased retinoic acid causes an expansion in the area and length of the vagal neuronal population, while retinoic acid depletion reduces the population. Consistent with this observation, the reduction in retinoic acid signaling levels in Zic2a2b-depleted embryos elicits a reduction in the size of the vagal neuron domain. Importantly, the vagal neuron domain in Zic2a2b-depleted embryos can be rescued by supplementation of RA to physiological levels.

\section{Conclusions}

We have identified a novel regulatory mechanism between Zic2a2b transcription factors and early retinoic acid signaling levels. We propose a model whereby Zic2a and Zic $2 b$ act upstream of both retinoic acid synthesis (aldh1a2) and degradation (cyp26a1) genes in an early embryo. We see a persistent reduction in retinoic acid signaling in Zic2a2b morphants at $26 \mathrm{hpf}$ that is similar
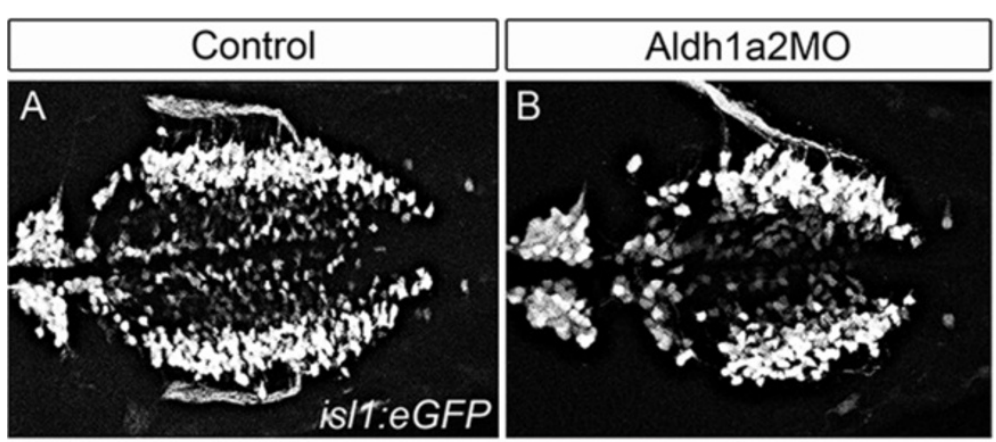

C

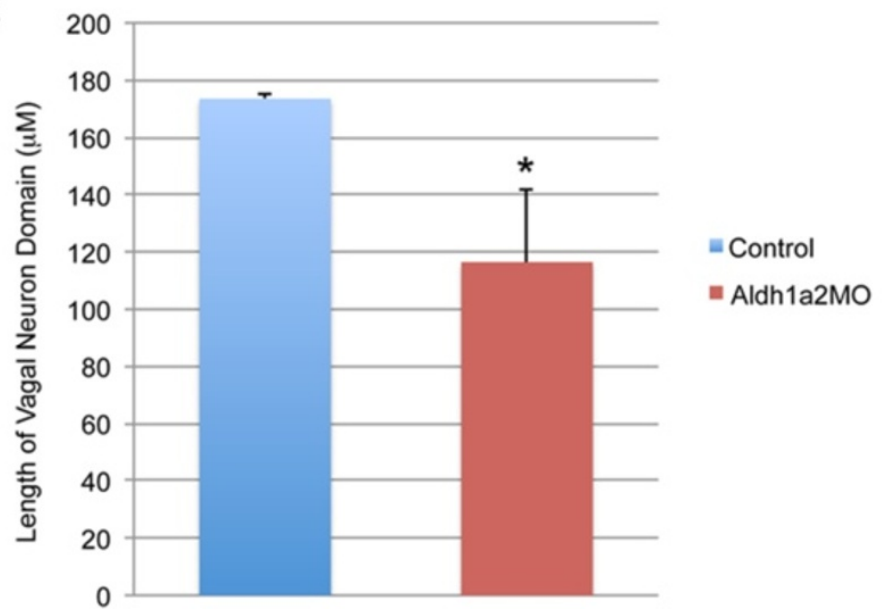

Figure 11 Knockdown of Aldh1a2 causes a reduction in the vagal neuron domain. Analysis of vagal motor neurons in Tg(is/1:eGFP) transgenic embryos injected with either a p53 control morpholino (1 ng, A) or an Aldh1a2 morpholino (2 ng, B). The length of the vagal domain was quantified using Image $J$ (C). Significance calculated using an unpaired t-test ${ }^{*} p$-value $\leq 0.01 ; n=2,6$ for quantification of $p 53 \mathrm{MO}$ and Aldh1a2 MO, respectively). 
to that observed in embryos depleted of the main retinoic acid synthesis enzyme, Aldh1a2. Consistent with reduced retinoic acid levels, Zic2a2b knockdown results in reduced vagal motor neuron formation within the posterior hindbrain and spinal cord. This phenotype is nearly identical to Aldh1a2-depleted embryos and is rescued by exogenous retinoic acid treatment.

While the role and requirement for retinoic acid metabolism genes has been well studied, less is known about the upstream regulators of these factors. During mouse development, Hoxa1-Pbx1 (Pre-B-cell leukemia homeobox 1) complexes directly regulate Raldh2 transcription within mesodermal tissue [66]. Additionally, deficiencies in zebrafish Tgif and Hmx4 cause defects associated with reduced retinoic acid levels and reduced aldh1a2 transcription [36,67]. Interestingly, Tgif-depletion also results in a concomitant reduction in cyp26a1 mRNA levels, similar to defects observed in Zic-depleted embryos. As expected, the Cyp26a1 murine mutant has defects associated with increased retinoic acid levels [41]. More notably, rescue of these defects is observed with heterozygous disruption of Aldh1a2 in a Cyp26a1 murine mutant, suggesting co-dependency between these genes, where less retinoic acid degradation is necessary when retinoic acid synthesis is reduced [38]. Thus, the fact that the transcription factors Zic2a and Zic2b regulate expression of both retinoic acid and synthesis genes strongly suggests that they play an important role in regulating retinoic acid levels during early embryogenesis.

Holoprosencephaly (HPE) is the most common forebrain birth defect, occurring when the cerebral hemispheres fail to separate. Mutations in human ZIC2 and TGIF are known to cause HPE. Our results from zebrafish studies provide evidence that both of these genes function to regulate RA metabolism [36]. Although both Zic and Tgif genes are implicated in regulating multiple signaling pathways, it is now plausible that altered levels of RA predispose embryos to HPE.

\section{Methods}

\section{Zebrafish care}

Danio rerio were maintained in accordance with published protocols [68]. Zebrafish adults and embryos were maintained at $28.5^{\circ} \mathrm{C}$. Embryos were raised in embryo medium (EM) with $10 \mathrm{ml} / \mathrm{l}$ Penicillin/Streptomycin (Sigma) added to prevent bacterial growth, and with phenyl-thiourea $(0.003 \%)$ used to prevent pigmentation after $24 \mathrm{hpf}$. The stage of developing embryos was assessed using reported morphological guidelines (Kimmel et al., 1995). Wild type $\mathrm{AB}, \operatorname{Tg}($ isl1:eGFP), and $\operatorname{Tg}(12 x R A R E$-ef1 $\mu$ : eGFP) strains were used as described [61-63]. Animal protocols were approved by the University of Alberta's Animal Care and Use Committee-Biosciences with protocol \#427.

\section{Morpholino injections}

Splice-blocking Zic2aMO [ $2 \mathrm{ng} / \mathrm{ml}$; 5-CTCACCTGAGA AGGAAAACATCATA-3'; [69]], splice-blocking Zic2bMO [2 ng/ml; 5'-CACGAATTGAAATAATTACCAGTGT-3'], splice-blocking Zic3MO [3 ng/ml; 5'-GGAATTTAATT TCCTTACCTGTGTG-3'], translation-blocking Aldh1a2 MO [2 ng/ml; 5'-GCAGTTCAACTTCACTGGAGGTCA T-3'; [54,70]], translation-blocking Cyp26a1MO [2 ng/ml; 5'-CGCGCAACTGATCGCCAAAACGAAA-3'; [71]], and p53MO morpholinos $[1 \mathrm{ng} / \mathrm{ml}]$ were designed to produce a non-functional protein [72]. Embryos were injected at the one-cell stage and allowed to develop until the desired time-point for phenotypic characterization.

\section{Examination of retinoic acid signaling}

To manipulate retinoic acid levels in developing zebrafish embryos, we used pharmacological treatment ( 1 or $5 \mathrm{nM}$ of all-trans retinoic acid (Sigma); 1 or $5 \mu \mathrm{M}$ diethylaminobenzaldehyde (DEAB, Sigma)) or morpholinos (Cyp26a1 or Aldh1a2) that target enzymes known to regulate degradation and synthesis of endogenous RA. Embryos were treated at approximately $50 \%$ epiboly with DEAB or RA in Embryo Medium, with DMSO and ethanol used as vehicle controls. Embryos were manually dechorionated at $26 \mathrm{hpf}$ and, maintaining treatment concentration, media was changed once per day. All treatments were carried out in $60 \mathrm{~mm}$ petri dishes each containing approximately $40 \mathrm{em}$ bryos grown at $28.5^{\circ} \mathrm{C} . \operatorname{Tg}(12 x R A R E-$ efla:eGFP $)$ transgenic zebrafish allow visualization of RA-signaling levels by assaying fluorescence (or by in situ hybridization for eGFP mRNA).

\section{Whole mount in situ hybridization}

mRNA in situ hybridization procedure is based on previously published methods [36]. Probes were synthesized via a PCR-based approach whereby primers are designed to amplify the 3' untranslated region (primer sequences available on request) [73]. Embryos of desired stage were fixed in $4 \%$ paraformaldehyde (PFA), permeabilized in Proteinase $\mathrm{K}(10 \mu \mathrm{g} / \mathrm{ml})$, re-fixed in $4 \%$ PFA and prehybridized for 2 hours at $65^{\circ} \mathrm{C} .100 \mu \mathrm{g}$ of probe was added and hybridization allowed to proceed overnight. Unbound probe was removed with three 20-minute high-stringency washes $(0.2 \times$ SSC $+0.1 \%$ Tween- $20 ; 0.1 \times$ SSC $+0.1 \%$ Tween-20; $0.1 \times$ SSC $+0.1 \%$ Tween-20). Embryos were first incubated in Blocking Solution (2\% Sheep Serum $+2 \mathrm{mg} / \mathrm{ml}$ Bovine Serum Albumin in PBST) for one hour at room temperature, or $4^{\circ} \mathrm{C}$ overnight, before transfer into primary antibody (Blocking Solution $+1 / 5000$ dilution of sheep anti-DIG-AP-FAB fragments antibody (Roche)) for two hours at room temperature, or $4^{\circ} \mathrm{C}$ overnight. Embryos are washed out of antibody using five-fifteen minute PBST washes. The coloration reaction is performed with either nitro-blue 
tetrazolium (NBT)/bromo-4-chloro-3-indolyl phosphate (BCIP) stock (Roche) in Coloration Buffer or, for embryos before bud stage, with BM purple (Roche). Coloration was stopped via $100 \%$ methanol/0.1\% Tween-20 washes. Deyolked embryos were dehydrated in 50\% glycerol, then $70 \%$ glycerol before mounting. Images are taken on Zeiss Axio Imager.Z1 using Axovision SE64 Rel.4.8 software. Embryos in early development (6-14 hpf) or with yolk attached are photographed on Olympus SZX12 stereoscope using QImaging micropublisher camera.

\section{JB-4 sectioning}

After in situ hybridization, embryos were post-fixed for 2 hours at room temperature in $4 \%$ paraformaldehyde. Embryos were then rinsed in PBS, dehydrated through a series of ethanol washes, and incubated over one hour in two rinses of JB-4 infiltration solution (made as per manufacturer's instructions, Polysciences Inc.). After transferring the embryos to molds, the infiltration solution was replaced with JB-4 embedding media and the blocks were left to harden at room temperature overnight. Seven $\mu \mathrm{M}$ sections were cut on a Leica RM2235 microtome and images were captured on a Zeiss Axio Imager.Z1 using Axovision SE64 Rel.4.8 software.

\section{Quantitative real-time PCR}

Quantitative Real-Time PCR was used to quantify in vivo mRNA levels to ascertain aldh1a2 gene expression in morpholino-injected embryos. Primers were designed using Roche Universal Probe Library for Zebrafish [Forward 5'-AACCACTGAACACGGACCTC-3' and Reverse 5'-ATGAGCTCCAGCACACGTC-3']. After RNA isolation (Ambion RNAqueous), DNA was removed by DNAseI digestion $\left(19 \mu \mathrm{l}\right.$ DEPC-treated $\mathrm{H}_{2} \mathrm{O}, 10 \mu \mathrm{l} 10 \times$ DNAseI buffer, $1 \mu \mathrm{l}$ DNAsel (Ambion)) for 30 minutes at $37^{\circ} \mathrm{C}$. RNA was further purified using Qiagen RNeasy columns and cDNA synthesized using AffinityScript qPCR cDNA Synthesis kit (Ambion) by the recommended protocol. Quantitative RT-PCR and primer validation was carried out as previously described [74,75]. For primer validation, control (AB) cDNA was isolated and used to create a dilution series: 1/8, 1/16, 1/32, 1/64, 1/128, 1/256. Ambion Brilliant II qPCR kit with thermocycler conditions $40 \times$ denaturation at $95^{\circ} \mathrm{C}$ for 30 seconds; annealing at $55^{\circ} \mathrm{C}$ for 1 minute; and extension at $72^{\circ} \mathrm{C}$ for 30 seconds. Finally, relative gene expression level was determined using the comparative $\mathrm{Ct}$ method ( $2^{-\Delta \Delta C t}$ method) and unpaired t-test calculations for significance [74,75]. Reaction mixtures and thermocycler program were identical to primer validation protocol; a $1 / 16$ dilution of experimental and control cDNA was used with each primer pair. Reactions were completed with at least 7 technical replicates from RNA isolated from 50 embryos, comparing to efla as endogenous control.

\section{Imaging of cranial motor neurons}

The $\mathrm{Tg}(i s l 1: e G F P)$ transgenic line allows visualization of a subset of motor neurons including those that are located within midbrain and hindbrain: oculomotor, trochlear, trigeminal, facial, glossopharyngeal, and vagal neurons [63]. For fluorescent analysis, embryos were fixed with 4\% PFA for 4 hours at room temperature. Yolks were removed manually and embryos dehydrated in 50\% and 70\% glycerol before mounting and imaging using a Zeiss LSM 510 confocal microscope and Zeiss Zen software. Image preparation and analysis (quantification of vagal neuron fluorescent area and length of vagal domain) was done with ImageJ software. To calculate vagal area, Z-stacked images were converted to 8-bit color and scale was set to correspond with that of image (pixel length 1024 or 2048, length of field of view $319.93 \mu \mathrm{m}$ ). Image threshold was set capturing the greatest number of neurons while keeping noise low. Regions of fluorescence were selected and the area calculated with numerical information transferred to Microsoft excel, where totals and averages were calculated. Statistical significance was determined using ANOVA followed by Tukey's HSD post hoc test, or by an unpaired $\mathrm{t}$-test.

\section{Competing interests}

The authors declare that they have no competing interests.

\section{Authors' contributions}

DLD conducted the studies of zic expression, morpholino knockdown, and analysis of retinoic acid signaling. CSC conducted studies of zic expression and assisted with writing the manuscript. LGS assisted with writing the manuscript and performed control experiments. JCH performed the JB-4 sectioning, helped with data analysis and edited the manuscript. LBP conducted studies of Zic function in regulating ocular retinoic acid levels and wrote the manuscript. AJW conceived of the study, participated in its design and wrote portions of the manuscript. All authors read and approved the final manuscript.

\section{Acknowledgements}

This research was supported by an operating grant from the Natural Sciences and Engineering Research Council (NSERC) award to AJW. Additional funding was obtained from Research, Scholarly Activity and Creative Achievement Fund (internal award from MacEwan University) awarded to LBP. DLD was the recipient of a Banting and Best scholarship from CIHR. LGS is the recipient of a Canadian Graduate Scholarship-Master's Award (NSERC). JCH is the recipient of an Alberta Innovates-Health Solutions postdoctoral fellowship. AJW is the recipient of a Canada Research Chair Award.

\section{Author details}

'Department of Biological Sciences, University of Alberta, CW405, Edmonton, AB T6G 2E9, Canada. ${ }^{2}$ Department of Biological Sciences, MacEwan University, Edmonton, Canada. ${ }^{3}$ Centre for Neuroscience, University of Alberta, Edmonton, Canada. 'Women \& Children's Health Research Institute, Edmonton, Canada.

Received: 15 April 2013 Accepted: 5 August 2013

Published: 12 August 2013

\section{References}

1. Chandrasekhar A, Moens CB, Warren JT Jr, Kimmel CB, Kuwada JY: Development of branchiomotor neurons in zebrafish. Development 1997, 124(13):2633-2644

2. Lumsden $\mathrm{A}$ : The cellular basis of segmentation in the developing hindbrain. Trends Neurosci 1990, 13(8):329-335. 
3. Lumsden A, Keynes R: Segmental patterns of neuronal development in the chick hindbrain. Nature 1989, 337(6206):424-428.

4. Moens $C B$, Prince VE: Constructing the hindbrain: insights from the zebrafish. Dev dyn off publ American Assoc Anatomists 2002, 224(1):1-17.

5. Wilkinson DG: Genetic control of segmentation in the vertebrate hindbrain. Perspect Dev Neurobiol 1995, 3(1):29-38.

6. Barrow JR, Stadler HS, Capecchi MR: Roles of Hoxa1 and Hoxa2 in patterning the early hindbrain of the mouse. Development 2000, 127(5):933-944

7. Bell $E$, Wingate RJ, Lumsden A: Homeotic transformation of rhombomere identity after localized Hoxb1 misexpression. Science 1999, 284(5423):2168-2171.

8. Cooper KL, Leisenring WM, Moens CB: Autonomous and nonautonomous functions for Hox/Pbx in branchiomotor neuron development. Dev Biol 2003, 253(2):200-213.

9. Ferretti $E$, Marshall $H$, Popperl $H$, Maconochie M, Krumlauf $R$, Blasi F: Segmental expression of Hoxb2 in $r 4$ requires two separate sites that integrate cooperative interactions between Prep1. Pbx and Hox proteins Dev 2000, 127(1):155-166.

10. Gavalas A, Davenne M, Lumsden A, Chambon P, Rijli FM: Role of Hoxa-2 in axon pathfinding and rostral hindbrain patterning. Development 1997, 124(19):3693-3702.

11. Gavalas A, Studer M, Lumsden A, Rijli FM, Krumlauf R, Chambon P: Hoxa1 and Hoxb1 synergize in patterning the hindbrain, cranial nerves and second pharyngeal arch. Development 1998, 125(6):1123-1136.

12. Helmbacher F, Pujades C, Desmarquet C, Frain M, Rijli FM, Chambon P, Charnay P: Hoxa1 and Krox-20 synergize to control the development of rhombomere 3. Development 1998, 125(23):4739-4748.

13. Krumlauf $R$, Marshall $H$, Studer M, Nonchev S, Sham MH, Lumsden A: Hox homeobox genes and regionalisation of the nervous system. J Neurobiol 1993, 24(10):1328-1340.

14. McClintock JM, Kheirbek MA, Prince VE: Knockdown of duplicated zebrafish hoxb1 genes reveals distinct roles in hindbrain patterning and a novel mechanism of duplicate gene retention. Development 2002, 129(10):2339-2354.

15. Prince VE, Moens CB, Kimmel CB, Ho RK: Zebrafish hox genes: expression in the hindbrain region of wild-type and mutants of the segmentation gene, valentino. Development 1998, 125(3):393-406.

16. Rossel M, Capecchi MR: Mice mutant for both Hoxa1 and Hoxb1 show extensive remodeling of the hindbrain and defects in craniofacial development. Development 1999, 126(22):5027-5040.

17. Studer M, Gavalas A, Marshall H, Ariza-McNaughton L, Rijli FM, Chambon P, Krumlauf R: Genetic interactions between Hoxa1 and Hoxb1 reveal new roles in regulation of early hindbrain patterning. Development 1998, 125(6):1025-1036

18. Wilkinson DG, Bhatt S, Cook M, Boncinelli E, Krumlauf R: Segmental expression of Hox-2 homoeobox-containing genes in the developing mouse hindbrain. Nature 1989, 341(6241):405-409.

19. Popperl $H$, Rikhof $H$, Chang $H$, Haffter $P$, Kimmel CB, Moens CB: lazarus is a novel pbx gene that globally mediates hox gene function in zebrafish. Mol Cell 2000, 6(2):255-267.

20. Waskiewicz AJ, Rikhof HA, Hernandez RE, Moens CB: Zebrafish Meis functions to stabilize $\mathrm{Pbx}$ proteins and regulate hindbrain patterning. Development 2001, 128(21):4139-4151.

21. Waskiewicz AJ, Rikhof HA, Moens CB: Eliminating zebrafish pbx proteins reveals a hindbrain ground state. Dev Cell 2002, 3(5):723-733.

22. Alexandre D, Clarke JD, Oxtoby E, Yan YL, Jowett T, Holder N: Ectopic expression of Hoxa-1 in the zebrafish alters the fate of the mandibular arch neural crest and phenocopies a retinoic acid-induced phenotype. Development 1996, 122(3):735-746.

23. Holder N, Hill J: Retinoic acid modifies development of the midbrain-hindbrain border and affects cranial ganglion formation in zebrafish embryos. Development 1991, 113(4):1159-1170.

24. Maden M: Heads or tails? Retinoic acid will decide. Bioessays 1999, 21(10):809-812.

25. Maden M, Gale E, Kostetskii I, Zile M: Vitamin A-deficient quail embryos have half a hindbrain and other neural defects. Curr Biol 1996, 6(4):417-426.

26. Maves L, Kimmel CB: Dynamic and sequential patterning of the zebrafish posterior hindbrain by retinoic acid. Dev Biol 2005, 285(2):593-605.

27. Papalopulu N, Clarke JD, Bradley L, Wilkinson D, Krumlauf R, Holder N: Retinoic acid causes abnormal development and segmental patterning of the anterior hindbrain in Xenopus embryos. Development 1991, 113(4):1145-1158.
28. van der Wees J, Schilthuis JG, Koster CH, Diesveld-Schipper H, Folkers GE, van der Saag PT, Dawson MI, Shudo K, van der Burg B, Durston AJ: Inhibition of retinoic acid receptor-mediated signalling alters positional identity in the developing hindbrain. Development 1998, 125(3):545-556.

29. Gongal PA, French CR, Waskiewicz AJ: Aberrant forebrain signaling during early development underlies the generation of holoprosencephaly and coloboma. Biochim Biophys Acta 2011, 1812(3):390-401.

30. Frasch $M$, Chen $X$, Lufkin T: Evolutionary-conserved enhancers direct region-specific expression of the murine Hoxa-1 and Hoxa-2 loci in both mice and Drosophila. Development 1995, 121(4):957-974.

31. Gould A, Itasaki N, Krumlauf R: Initiation of rhombomeric Hoxb4 expression requires induction by somites and a retinoid pathway. Neuron 1998, 21(1):39-51.

32. Morrison A, Ariza-McNaughton L, Gould A, Featherstone M, Krumlauf R: HOXD4 and regulation of the group 4 paralog genes. Development 1997, 124(16):3135-3146.

33. Yan $Y L$, Jowett $T$, Postlethwait JH: Ectopic expression of hoxb2 after retinoic acid treatment or $\mathrm{mRNA}$ injection: disruption of hindbrain and craniofacial morphogenesis in zebrafish embryos. Dev dyn off publ American Assoc Anatomists 1998, 213(4):370-385.

34. Niederreither $K$, Subbarayan V, Dolle P, Chambon P: Embryonic retinoic acid synthesis is essential for early mouse post-implantation development. Nat Genet 1999, 21(4):444-448.

35. Niederreither K, Vermot J, Schuhbaur B, Chambon P, Dolle P: Retinoic acid synthesis and hindbrain patterning in the mouse embryo. Development 2000, 127(1):75-85.

36. Gongal PA, Waskiewicz AJ: Zebrafish model of holoprosencephaly demonstrates a key role for TGIF in regulating retinoic acid metabolism. Hum Mol Genet 2008, 17(4):525-538.

37. Abu-Abed S, Dolle P, Metzger D, Beckett B, Chambon P, Petkovich M: The retinoic acid-metabolizing enzyme, CYP26A1, is essential for normal hindbrain patterning, vertebral identity, and development of posterior structures. Genes dev 2001, 15(2):226-240.

38. Niederreither K, Abu-Abed S, Schuhbaur B, Petkovich M, Chambon P, Dolle $P$ : Genetic evidence that oxidative derivatives of retinoic acid are not involved in retinoid signaling during mouse development. Nat Genet 2002, 31(1):84-88.

39. de Roos K, Sonneveld E, Compaan B, ten Berge D, Durston AJ, van der Saag PT: Expression of retinoic acid 4-hydroxylase (CYP26) during mouse and Xenopus laevis embryogenesis. Mech Dev 1999, 82(1-2):205-211.

40. Hernandez RE, Putzke AP, Myers JP, Margaretha L, Moens CB: Cyp26 enzymes generate the retinoic acid response pattern necessary for hindbrain development. Development 2007, 134(1):177-187.

41. Sakai Y, Meno C, Fujii H, Nishino J, Shiratori H, Saijoh Y, Rossant J, Hamada $H$ : The retinoic acid-inactivating enzyme CYP26 is essential for establishing an uneven distribution of retinoic acid along the anterioposterior axis within the mouse embryo. Genes dev 2001, 15(2):213-225.

42. Sirbu IO, Gresh L, Barra J, Duester G: Shifting boundaries of retinoic acid activity control hindbrain segmental gene expression. Development 2005, 132(11):2611-2622

43. Swindell EC, Thaller C, Sockanathan S, Petkovich M, Jessell TM, Eichele G: Complementary domains of retinoic acid production and degradation in the early chick embryo. Dev Biol 1999, 216(1):282-296.

44. Brand N, Petkovich M, Krust A, Chambon P, de The H, Marchio A, Tiollais P, Dejean A: Identification of a second human retinoic acid receptor. Nature 1988, 332(6167):850-853.

45. de The H, Marchio A, Tiollais P, Dejean A: A novel steroid thyroid hormone receptor-related gene inappropriately expressed in human hepatocellular carcinoma. Nature 1987, 330(6149):667-670.

46. Petkovich M, Brand NJ, Krust A, Chambon P: A human retinoic acid receptor which belongs to the family of nuclear receptors. Nature 1987, 330(6147):444-450.

47. Gould A, Morrison A, Sproat G, White RA, Krumlauf R: Positive cross-regulation and enhancer sharing: two mechanisms for specifying overlapping Hox expression patterns. Genes dev 1997, 11(7):900-913.

48. Popperl H, Bienz M, Studer M, Chan SK, Aparicio S, Brenner S, Mann RS, Krumlauf R: Segmental expression of Hoxb-1 is controlled by a highly conserved autoregulatory loop dependent upon exd/pbx. Cell 1995, 81(7):1031-1042.

49. Maurus D, Harris WA: Zic-associated holoprosencephaly: zebrafish Zic1 controls midline formation and forebrain patterning by regulating 
Nodal, Hedgehog, and retinoic acid signaling. Genes dev 2009, 23(12):1461-1473.

50. Brown LY, Odent S, David V, Blayau M, Dubourg C, Apacik C, Delgado MA, Hall BD, Reynolds JF, Sommer A, et al: Holoprosencephaly due to mutations in ZIC2: alanine tract expansion mutations may be caused by parental somatic recombination. Hum Mol Genet 2001, 10(8):791-796.

51. Brown SA, Warburton D, Brown LY, Yu CY, Roeder ER, Stengel-Rutkowski S, Hennekam RC, Muenke M: Holoprosencephaly due to mutations in ZIC2, a homologue of Drosophila odd-paired. Nat Genet 1998, 20(2):180-183.

52. Gripp KW, Wotton D, Edwards MC, Roessler E, Ades L, Meinecke P, Richieri-Costa A, Zackai EH, Massague J, Muenke M, et al: Mutations in TGIF cause holoprosencephaly and link NODAL signalling to human neural axis determination. Nat Genet 2000, 25(2):205-208.

53. Wallis DE, Muenke M: Molecular mechanisms of holoprosencephaly. Mol Genet Metab 1999, 68(2):126-138.

54. Begemann G, Schilling TF, Rauch GJ, Geisler R, Ingham PW: The zebrafish neckless mutation reveals a requirement for raldh2 in mesodermal signals that pattern the hindbrain. Development 2001, 128(16):3081-3094.

55. Linville A, Gumusaneli E, Chandraratna RA, Schilling TF: Independent roles for retinoic acid in segmentation and neuronal differentiation in the zebrafish hindbrain. Dev Biol 2004, 270(1):186-199.

56. Dobbs-McAuliffe B, Zhao Q, Linney E: Feedback mechanisms regulate retinoic acid production and degradation in the zebrafish embryo. Mech Dev 2004, 121(4):339-350.

57. Emoto Y, Wada H, Okamoto H, Kudo A, Imai Y: Retinoic acid-metabolizing enzyme Cyp26a1 is essential for determining territories of hindbrain and spinal cord in zebrafish. Dev Biol 2005, 278(2):415-427.

58. Elsen GE, Choi LY, Millen KJ, Grinblat Y, Prince VE: Zic1 and Zic4 regulate zebrafish roof plate specification and hindbrain ventricle morphogenesis. Dev Biol 2008, 314(2):376-392.

59. Grinblat $Y$, Sive H: zic Gene expression marks anteroposterior pattern in the presumptive neurectoderm of the zebrafish gastrula. Dev dyn off publ American Assoc Anatomists 2001, 222(4):688-693.

60. Nyholm MK, Abdelilah-Seyfried S, Grinblat Y: A novel genetic mechanism regulates dorsolateral hinge-point formation during zebrafish cranial neurulation. J cell sci 2009, 122(Pt 12):2137-2148.

61. Feng L, Hernandez RE, Waxman JS, Yelon D, Moens CB: Dhrs3a regulates retinoic acid biosynthesis through a feedback inhibition mechanism. Dev Biol 2010, 338(1):1-14.

62. Waxman JS, Yelon D: Zebrafish retinoic acid receptors function as contextdependent transcriptional activators. Dev Biol 2011, 352(1):128-140.

63. Higashijima S, Hotta Y, Okamoto H: Visualization of cranial motor neurons in live transgenic zebrafish expressing green fluorescent protein under the control of the islet-1 promoter/enhancer. J Neurosci 2000, 20(1):206-218.

64. Maden M, Sonneveld E, van der Saag PT, Gale E: The distribution of endogenous retinoic acid in the chick embryo: implications for developmental mechanisms. Development 1998, 125(21):4133-4144.

65. Ohishi K, Nishikawa S, Nagata T, Yamauchi N, Shinohara H, Kido J, Ishida H: Physiological concentrations of retinoic acid suppress the osteoblastic differentiation of fetal rat calvaria cells in vitro. Eur $j$ endocrinol Eur Fed Endocr Soc 1995, 133(3):335-341.

66. Vitobello A, Ferretti E, Lampe X, Vilain N, Ducret S, Ori M, Spetz JF, Selleri L, Rijli FM: Hox and Pbx factors control retinoic acid synthesis during hindbrain segmentation. Dev Cell 2011, 20(4):469-482.

67. Gongal PA, March LD, Holly VL, Pillay LM, Berry-Wynne KM, Kagechika H, Waskiewicz AJ: Hmx4 regulates Sonic hedgehog signaling through control of retinoic acid synthesis during forebrain patterning. Dev Biol 2011, 355(1):55-64

68. Westerfield M: The zebrafish book. A guide for the laboratory use of zebrafish (Danio rerio), 4th edition edn. Eugene, OR: Univ. of Oregon Press; 2000.

69. Nyholm MK, Wu SF, Dorsky Rl, Grinblat Y: The zebrafish zic2a-zic5 gene pair acts downstream of canonical Wnt signaling to control cell proliferation in the developing tectum. Development 2007, 134(4):735-746.

70. Alexa K, Choe SK, Hirsch N, Etheridge L, Laver E, Sagerstrom CG: Maternal and zygotic aldh1a2 activity is required for pancreas development in zebrafish. PloS one 2009, 4(12):e8261.

71. Kudoh T, Wilson SW, Dawid IB: Distinct roles for Fgf, Wnt and retinoic acid in posteriorizing the neural ectoderm. Development 2002, 129(18):4335-4346.

72. Robu ME, Larson JD, Nasevicius A, Beiraghi S, Brenner C, Farber SA, Ekker SC: p53 activation by knockdown technologies. PLoS genetics 2007, 3(5):e78.
73. Thisse C, Thisse B: High-resolution in situ hybridization to whole-mount zebrafish embryos. Nat Protoc 2008, 3(1):59-69.

74. Livak KJ, Schmittgen TD: Analysis of relative gene expression data using real-time quantitative PCR and the 2(-Delta Delta C(T)) Method. Methods 2001, 25(4):402-408.

75. Pillay LM, Forrester AM, Erickson T, Berman JN, Waskiewicz AJ: The Hox cofactors Meis1 and Pbx act upstream of gata1 to regulate primitive hematopoiesis. Dev Biol 2010, 340(2):306-317.

doi:10.1186/1471-213X-13-31

Cite this article as: Drummond et al:: The role of Zic transcription factors in regulating hindbrain retinoic acid signaling. BMC Developmental

Biology 2013 13:31.

\section{Submit your next manuscript to BioMed Central and take full advantage of:}

- Convenient online submission

- Thorough peer review

- No space constraints or color figure charges

- Immediate publication on acceptance

- Inclusion in PubMed, CAS, Scopus and Google Scholar

- Research which is freely available for redistribution

Submit your manuscript at www.biomedcentral.com/submit
Ciomed Central 